Telescope shows images of the same double star with HST and NOT which gives the impression that HST vastly outperforms NOT in image sharpness. Yet the HST image was processed so as to show only the core of the image, containing just 15 per cent of the light. In particular, the large faint halo, more than 2 arc-seconds in diameter, was not shown.

It is difficult to understand why a picture such as this should have been made public. The presence of spherical aberration must have been known when the false picture was made. Did those responsible believe that the faults of the HST mirrors could be concealed in that way?

Now that the truth about the HST is known, the widely distributed false pictures must give many people the impression that the imaging quality of the NOT is even worse. Clearly the NOT images shown were obtained during mediocre seeing conditions; they are by no means typical of those provided by the telescope. Indeed, the observing logbook shows that the seeing is better than 1 arc-second for 65 per cent of the time, and even less than 0.5 arc-seconds for 7 per cent of the time.

It is especially ironic that NASA and ESA should have used NOT images to illustrate their claim of the superiority of HST over ground-based telescopes when NOT is one of the few telescopes that consistently give sharper images than HST in its present state. I believe that this unfair comparison has thrown mud at the reputation of NOT, which is why the astronomy and scientific community should know that the image sharpness of our telescope is second to none.

By way of demonstration, the object in the accompanying image of the gravitational lens object QSO $2237+0305$, also known as the Einstein cross, has a maximum diameter of only 1.7 arc-seconds, of the same order as the single stellar images with NOT shown in the HST advertisement. With other telescopes, the four quasar images and the nucleus of the lensing galaxy are resolved only in exceptionally good conditions. For NOT, this is possible on most clear nights.

\section{Turku University Observatory,}

TAPIO KORHONEN

Tuorla,

21500 Piikkiö, Finland

\title{
Hydrothermal vents in Lake Baikal
}

$\mathrm{S}_{\mathrm{IR}}$ - Our discovery in mid-1990, in conjunction with a team from the National Geographical Society, of hydrothermal vents in Lake Baikal, confirms heat-flow and watercolumn temperature anomalies previously reported $^{1-3}$. The vents were found at a depth of $440 \mathrm{~m}$ on the sediment floor of Frolikha Bay (in the northeastern corner of Lake Bai$\mathrm{kal}$ ), at the foot of an east-west trending fault. Investigations were conducted from on board a ship fitted with two global positioning satellite receivers for navigation, with an accuracy of better than $100 \mathrm{~m}, 3.5$ and 12

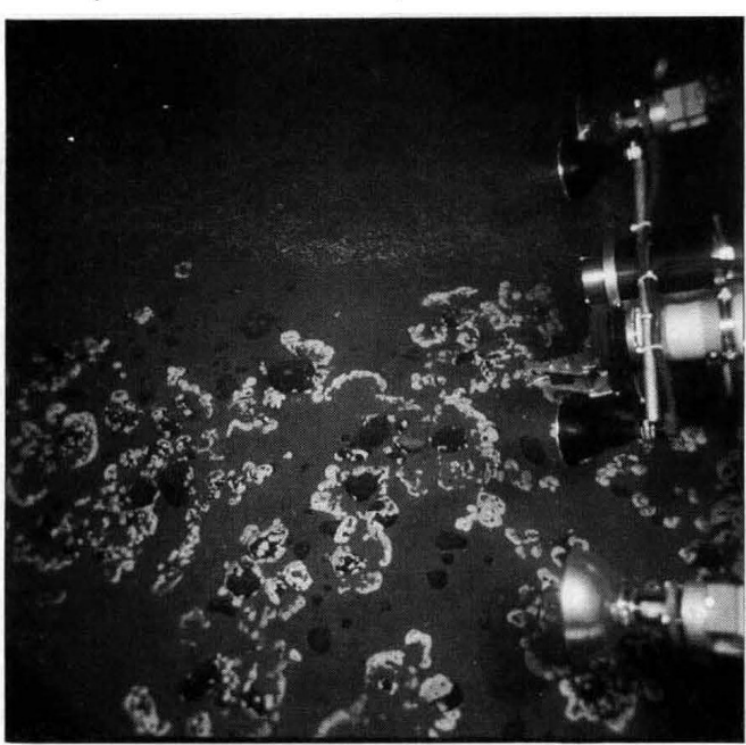

Low-angle oblique view of the Frolikha Bay vent site. In the foreground are sponges encrusting cobbles at the periphery of the vent field. In the background is a mat of filamentous bacteria resting on sediment closer to the centre of the vent field. Photograph taken by Emory Kristof, National Geographical Society. the lake may have been connected to the oceans. How the taxa inhabiting the Lake Baikal hydrothermal vents fit into the biogeographical arena of vent communities needs more detailed investigation, but promises to provide interesting clues to the evolutionary history of these intriguing communities, as well as of Lake Baikal itself.

Unlike hydrothermal venting along the mid-ocean-ridge system, which occurs primarily along or near the axis of spreading, the hydrothermal vents in Lake Baikal occur along a flanking fault zone more than $18 \mathrm{~km}$ from the axis of the rift valley floor. This relationship between flanking faults and high heat flow is consistent with geothermal surveys in the central part of the tectonically similar East African Rift ${ }^{4}$. The difference in setting between oceanic vents and continental-rift vents is thought to be a response to the different quantities of magma beneath. Along, most mid-ocean ridges, where magma is plentiful and located primarily along the axis of spreading, axial fissures and faults act as central conduits for water entrances and exits (K. C. F. Aikman, D. Altman \& J. Perlin, manuscript submitted). Under the continental rift, however, magma is scarce and the young rift is dominated by tectonic activity, for example, deeply incised, flanking faults. Magma bodies are either at great depth or nonexistent. Therefore meteoric water that enters flanking faults sinks to great depth, is heated by an enhanced geothermal gradient and then erupts back onto the surface along the same system of faults by which it entered the subterranean world. This fault-controlled hydrothermal exchange may have a substantial effect on the chemistry and the stability of the Lake Baikal water column. The tectonic setting of hydrothermal vents in Lake Baikal may provide clues to its degree of evolution as a continental rift.

Lake Baikal and its associated rift contain biological and geological evidence linking the lake's origin to the birth of an infant ocean. The degree to which Baikal has evolved from a purely continental arena into its transition between a lake and a sea can only be deciphered by additional exploration.

consists of vent-specific ta is merely a dense concentration of background lake fauna is not known. However, no similar concentrations of organisms, or sponges with the same growth form, are seen in areas removed from the vent field (approximately $85 \%$ of the photographs). Patches of dark grey sediment and patches of sediment pock-marked by thousands of small holes (burrows?) are also seen at the edge of the vent field.

The fauna of Lake Baikal is unique in its high degree of endemism and in the number of species that have affinities to saltwater forms, suggesting that

Department of Geology and

Kathleen Crane

Geography,

Hunter College,

695 Park Avenue, New York,

New York 10021, USA

Lamont-Doherty Geological

Observatory,

Palisades, New York 10964, USA

Institute of the Earth's Crust,

Vladimir Golubev

U1 Lermontora, 128,

664033 Irkutsk, USSR

1. Golubev, V. Akademia Nauk SSSR 6, 75-89 (1981)

2. Golubev, V. Akademia Nauk SSSR 1, 104-107 (1984)

3. Lysak, S. B. Tectonophysics 103, 205-215 (1984).

4. Crane, K. \& O'Connell, S. Tectonophysics $\mathbf{9 4}, 253-275$ (1983). 